\title{
Oculomotricidade e seus fundamentos
}

\author{
Ocular motility:foundations
}

Harley E. A. Bicas

\begin{tabular}{|c|}
\hline RESUMO \\
\hline 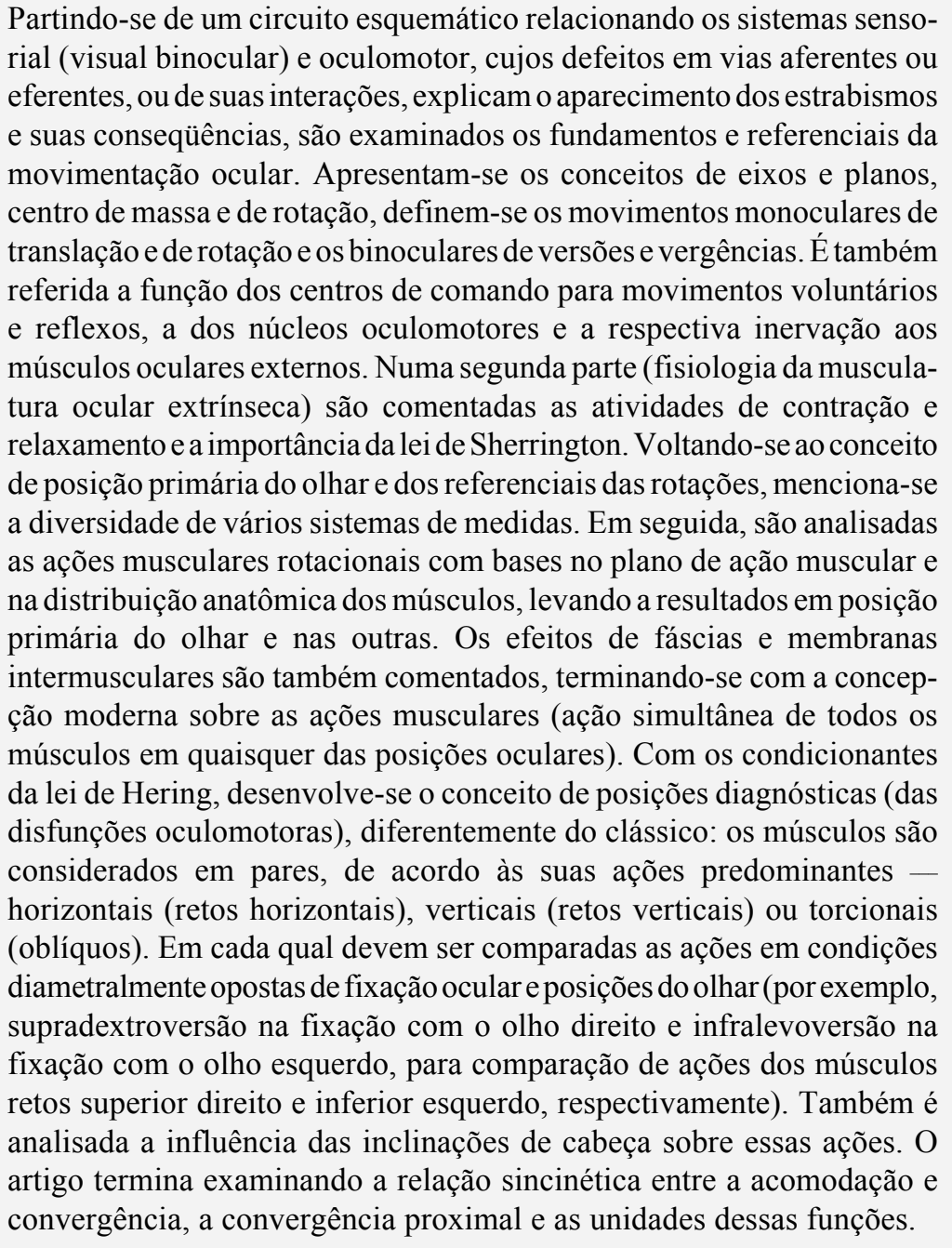 \\
\hline
\end{tabular}

Descritores: Estrabismo; Movimentos oculares; Rotação ocular; Medidas; Músculos oculomotores; Nervo oculomotor; Acomodação ocular; Convergência ocular; Oftalmopatias

Professor Titular, Departamento de Oftalmologia, Otorrinolaringologia e Cirurgia de Cabeça e Pescoço, Faculdade de Medicina de Ribeirão Preto da Universidade de São Paulo

Endereço para correspondência: Dep. de OFT/ORL/ CCP - Fac. Méd. Ribeirão Preto -USP - Av. Bandeirantes, 3.900 - Ribeirão Preto (SP) CEP 14049-900 
Com desempenhos garantidos pelas respostas de doze músculos oculares externos (seis em cada olho), acionados por três pares de nervos craniais, cujos estímulos dependem de interações entre os comandos volitivos a essa movimentação e os de reações automáticas complementares, o sistema oculomotor mantém, ademais, uma rigorosa cooperação com as funções sensoriais visuais binoculares. Constitui-se, assim, um conjunto ainda mais complexo e de firme interdependência entre visão (mono e binocular) e oculomotricidade, demandas e estímulos, centros de comandos e respostas, em que causas e conseqüências se misturam. Daí, também, a sua vulnerabilidade, explicando uma prevalência relativamente alta (cerca de 5\%) para os desequilíbrios manifestos do sistema oculomotor (estrabismos) e seus distúrbios correla$\operatorname{tos}^{(1)}$, mas ainda maior se outras formas latentes, ou compensadas (heteroforias) e incoordenações (nistagmos, dissinergias, etc.) forem também consideradas.

As interações entre os sistemas sensorial (visual) binocular e oculomotor podem ser simplificadamente esquematizadas pela figura 1. O rompimento de quaisquer das comunicações sucessivas ou defeito de uma das estruturas de transição (dos estímulos e, ou comandos) desestrutura o conjunto, causando-lhe desequilíbrio. Assim, defeitos primários do sistema sensorial, tais como impedimentos à formação adequada de imagens ópticas do objeto (opacificações de meios oculares transparentes, ametropias), lesões de retina, nervo óptico, vias visuais ou áreas corticais, enfim quaisquer causas de má visão, são também determinantes de desequilíbrios da coordenação oculomotora. Por outro lado, afecções originárias do sistema oculomotor (centros ou vias de comando supranucleares, lesões de nervos, miopatias, etc.) produzem distúrbios no posicionamento e movimentação dos olhos, do que resultam inadequações da integração visual binocular das imagens (diplopias, confusões), com os decorrentes mecanismos defensivos (supressões). A conseqüência é a perda da capacidade da discriminação visual fina das distâncias egocêntricas (perdas de estereopsia) e, nos casos em que o defeito motor ocorre na infância, a possível deterioração da função visual do olho que se mantém desviado (ambliopia). Enfim, nos estrabismos, reconhecidos pela população leiga como representando apenas um defeito da estética fisionômica (e cujas conseqüências são as de prejuízos da auto-estima, do relacionamento afetivo e psicossocial) há, também, perdas visuais importantes e eventualmente irreversíveis, sejam elas causas primárias do desvio (por exemplo, lesões de coriorretinite, retinoblastomas, neurites ópticas), ou conseqüências dele (ambliopias). Em alguns casos, podem ser achados para cada olho, independentemente, desempenhos visuais discriminativos normais; mas estará ausente a capacidade de cooperação entre eles; isto é, a visão binocular achar-se-á sempre prejudicada (mesmo no caso em que puder ser demonstrada boa visão para cada olho).

Algumas dessas condições serão mais pormenorizadamente examinadas em artigo futuro (sobre a fisiologia da visão binocular). Mas uma vez situada a importância da motilidade ocular em seu contexto genérico, podemos agora passar a aspectos introdutórios de suas particularidades.

\section{A) Fundamentos e referenciais}

Movimentos oculares são definidos como sendo de translação ou de rotação, com respeito a um conjunto referencial de eixos e planos externos ao olho e dele próprio $^{(2-3)}$.

\section{1) Centro de massa}

Também conhecido como "centro de gravidade", representa o ponto imaginário no qual estaria concentrada toda a matéria (e daí, o "peso") do olho ou, equivalentemente, o ponto em torno do qual ela estaria homogeneamente distribuida. Esse conceito físico, útil para o estudo de como se comporta um objeto quando sob ação de forças sobre ele aplicadas é mera abstração, já que o olho não está isolado no espaço, mas envolto por estruturas e contido entre paredes orbitárias, o que lhe confere uma relativa estabilidade espacial dentro desse invólucro ósseo.

\section{2) Centro de rotação}

É o ponto do olho teoricamente fixo em relação à órbita, mesmo sob ação de forças. Define-se, aliás, a rotação ocular como o movimento em que todos os pontos do olho são movidos em torno de um, fixo (o centro de rotação) ${ }^{(2)}$.

Um centro de rotação único é classicamente admitido como estando situado a 1,6 $\mathrm{mm}$ do lado nasal e 1,3 $\mathrm{mm}$ atrás do centro geométrico do olho ${ }^{(4)}$. Entretanto, essa é uma teorização reducionista, já que não existe um ponto único e fixo para todas as rotações. Principalmente na dependência do sentido em que elas ocorrem, muda o ponto imaginário (relativamente à órbita), em torno do qual cada movimento se faz. Assim, emerge o conceito do "centrodo", o centro da superfície determinada pelo conjunto dos centros instantâneos das rotações oculares ${ }^{(4-5)}$.

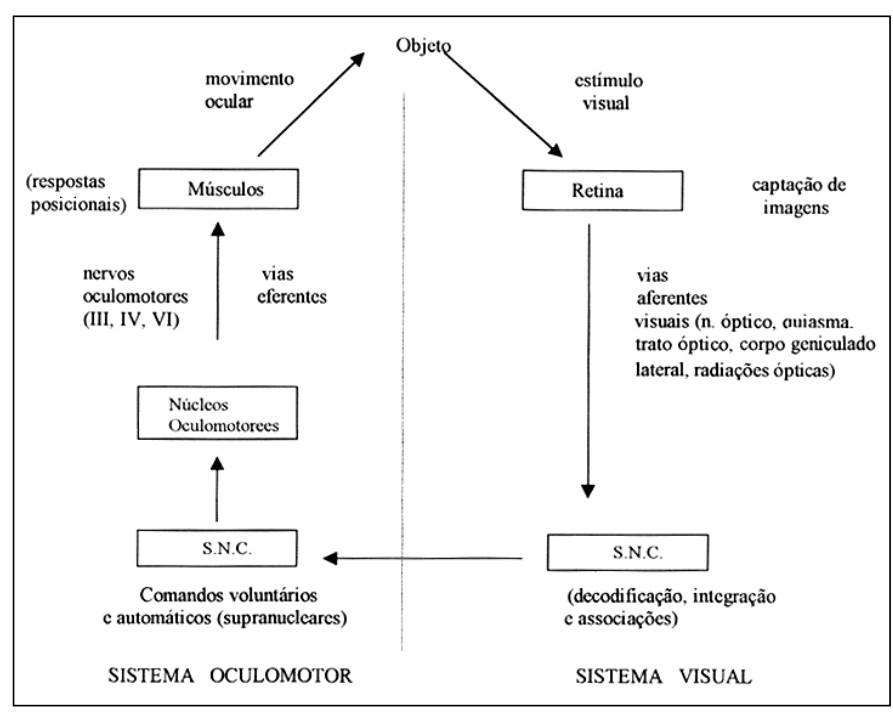

Figura 1 - Diagrama de blocos esquematizando a interação entre o sistema sensorial (visual binocular), à direita, e o oculomotor (à esquerda) 


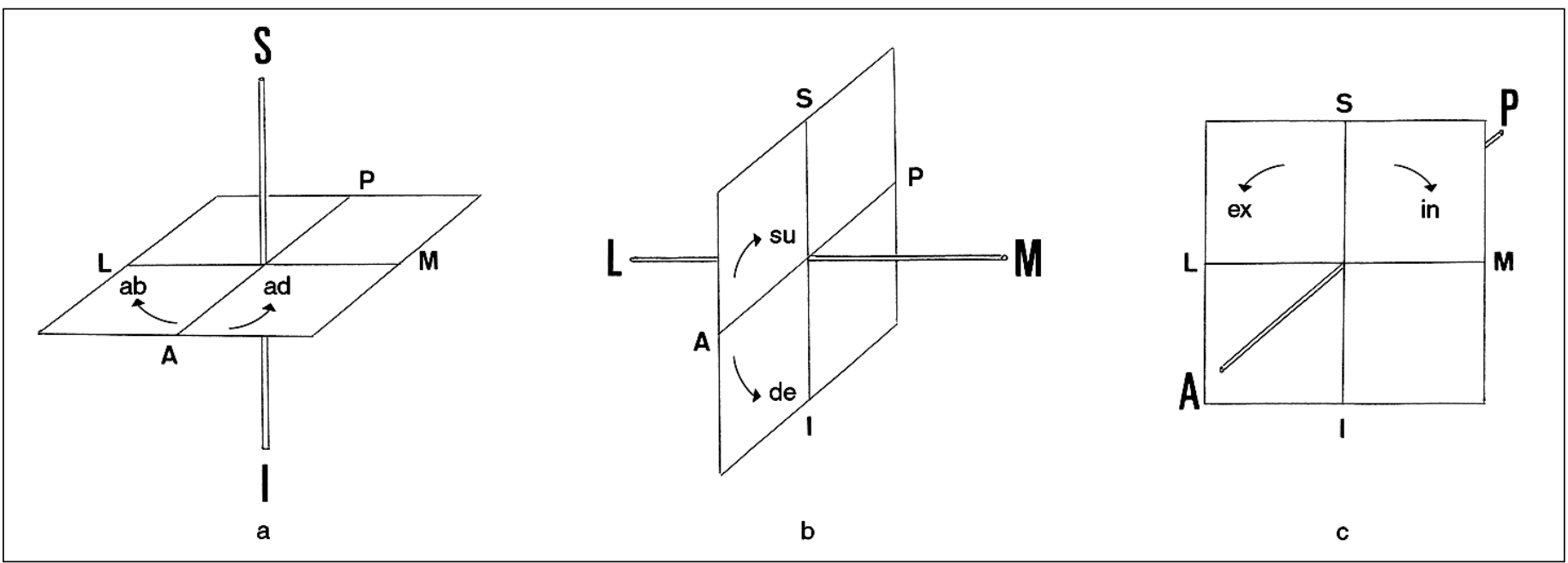

Figura 2 - Sistema referencial (eixos e planos) para as rotações oculares. (a): plano horizontal, no qual são definidas as rotações horizontais de adução (ad) e abdução (ab), em torno do eixo vertical (SI); (b): plano sagital, no qual são definidas as rotações verticais de sursundução (su) ou elevação e deorsundução (de) ou abaixamento, em torno do eixo transversal (LM); (c): plano frontal, no qual são definidas as rotações torcionais de exciclodução ou extorção (ex) e de inciclodução ou intorção (in), em torno do eixo longitudinal. (AP)

Para quase todos os efeitos práticos, a coincidência entre o centro de rotação (ideal e abstrato) e o centro geométrico do olho não traz conseqüências.

\section{3) Eixos e planos}

O ponto fixo, imaginário e ideal, em torno do qual são feitas e definidas as rotações oculares, é considerado a origem de um sistema ortogonal de coordenadas espaciais, com três eixos: o vertical, ou súpero-inferior; o transversal, ou láteromedial; e o longitudinal, ou ântero-posterior. Por eles, são também definidos três planos: o horizontal (atravessado perpendicularmente pelo vertical e contendo os eixos transversal e longitudinal), o sagital (atravessado perpendicularmente pelo eixo transversal e contendo os eixos vertical e longitudinal) e o frontal (atravessado perpendicularmente pelo eixo longitudinal e contendo os eixos vertical e transversal).

\section{4) Rotações monoculares (duções)}

As rotações são definidas, em torno dos eixos referidos:

a) As horizontais, no plano horizontal, isto é, em torno do eixo vertical: adução, quando o pólo anterior do olho aproxima-se do lado nasal (medial) e abdução, quando se aproxima do lado temporal (lateral) (Figura 2a).

b) As verticais, no plano sagital, isto é, em torno do eixo transversal: sursundução (ou elevação) ${ }^{(*)}$, quando o pólo anterior do olho aproxima-se do lado superior e deorsundução (ou abaixamento) ${ }^{(*)}$, quando em sentido contrário (Figura 2b).

c) As torcionais, no plano frontal, isto é, em torno do eixo longitudinal: exciclodução (ou exciclotorção), quando o

(*) Os termos "elevação" e "abaixamento", ou "depressão", muito usados para as rotações verticais, podem causar confusão com a terminologia empregada para a definição de translações. pólo superior do olho gira para o lado temporal e inciclodução (ou inciclotorção) quando o pólo superior se aproxima do lado nasal (Figura 2c).

\section{5) Translações}

As translações são definidas como o movimento conjunto de todos os pontos do olho ao longo de uma direção do espaço. As fundamentais são as que se dão:

a) Ao longo do eixo vertical, como ascensão (as), ou elevação, ou subida (quando todo o olho se desloca em sentido do pólo superior), ou como descensão (ds), ou depressão, ou descida (quando em sentido inverso) (Figura 3a).

b) Ao longo do eixo horizontal, como introversão (it), ou deslocamento medial (quando o olho se desloca para o lado medial da órbita) e lateriversão (la), ou deslocamento lateral (quando para o lado lateral) (Figura 3b).

c) Ao longo do eixo longitudinal, extrusão, ou protrusão (pr), ou avanço (quando o olho se anterioriza na órbita) e intrusão, ou retrotração (re), ou retrocesso (quando o olho é deslocado para trás, na órbita (Figura 3c). A protrusão causa a exoftalmia e a intrusão a enoftalmia.

Claro que as translações podem se dar ao longo de eixos inclinados em relação aos fundamentais (assim como as rotações), sendo entretanto seus componentes vetoriais definidos relativamente àqueles.

As translações são geralmente de pequena magnitude (milímetros) e relacionadas a processos orbitários: neoplasias, infiltrações generalizadas de tecidos perioculares (a exoftalmia da doença de Basedow-Graves), fraturas de assoalho (da órbita), etc. Algumas vezes, devidas à ação conjunta de músculos oculares externos de sentido antagônico (como na cocontração dos retos horizontais à tentativa de adução na síndrome de Duane), causando a retrotração ocular ${ }^{(2-3)}$. 


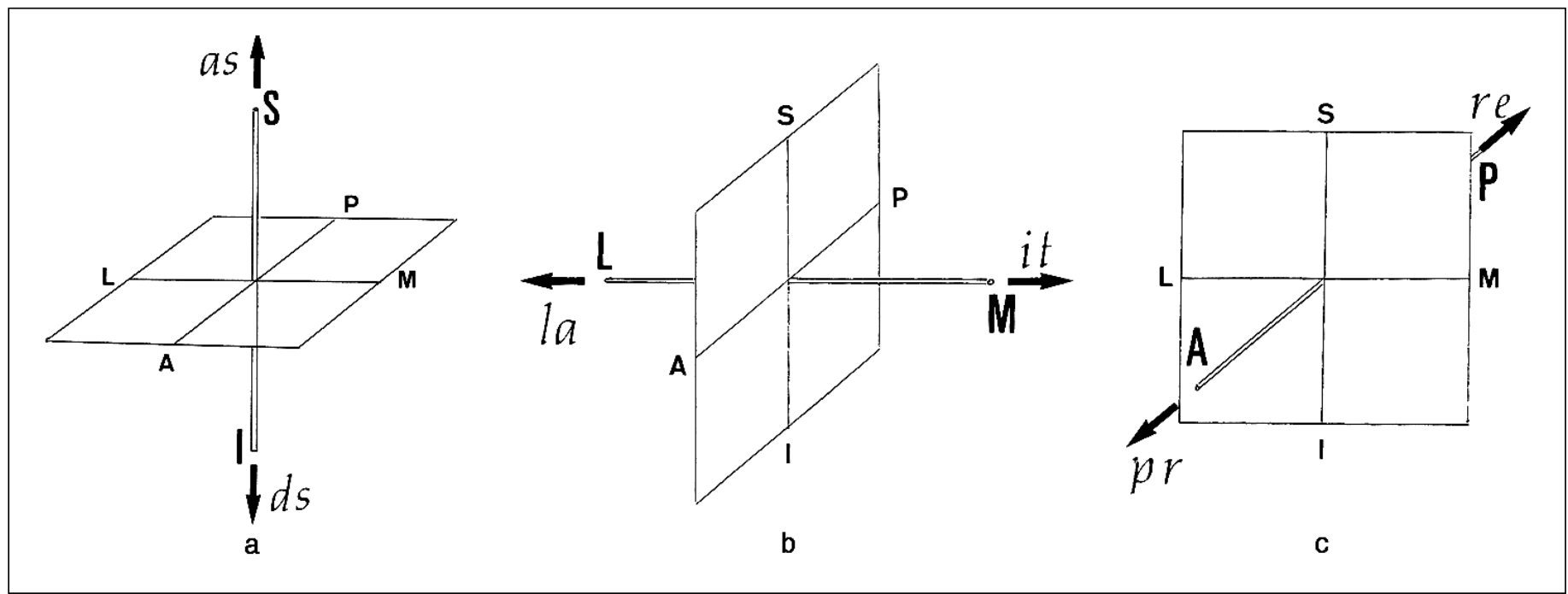

Figura 3 - Definição das translações oculares: (a) ao longo do eixo vertical (SI) como ascensão (as) ou subida e como descensão (ds) ou descida; (b): ao longo do eixo transversal, como introversão (it) e lateriversão (la); (c): ao longo do eixo longitudinal, como protrusão (pr), dando exoftalmia e como intrusão ou retrotração (re), dando enoftalmia

\section{B) Músculos oculares externos e suas ações ${ }^{(5-6)}$}

\section{1) Comandos corticais para movimentos voluntários}

Embora seja possível que outras áreas corticais também promovam rotações oculares volitivamente desejadas, os estímulos para tais respostas partem principalmente de áreas corticais frontais (giro pré-central ou partes das convoluções frontais adjacentes) e chegam ao pedúnculo cerebral por meio do chamado trato oculogírico (ou córtico-nuclear). Admite-se que as vias sejam cruzadas, alcançando os centros "intermediários" (para movimentos verticais ou horizontais conjugados) contralaterais. Por exemplo, a área frontal esquerda comandaria movimentos horizontais para a direita.

\section{2) Comandos corticais para movimentos reflexos}

Movimentos automáticos, também chamados psico-ópticos (como o de fixação, o de refixação, o de convergência e os de fusão binocular) são originados no lobo occipital.

\section{3) Movimentos binoculares}

Como resposta aos comandos corticais, sejam eles voluntários ou automáticos, dois tipos fundamentais de movimentos binoculares podem ocorrer: os conjugados (versões) e os disjuntivos (vergências).

\section{a) Versões}

Chamam-se versões, ou movimentos binoculares conjugados, aqueles que se dão no mesmo sentido corporal, isto é, para a direita (dextroversão), para a esquerda (levoversão), para cima (sursunversão), ou para baixo (deorsunversão). Esses movimentos acima descritos, no plano horizontal (os dois primeiros) e no sagital (os dois últimos) são voluntários, embora também possam ser suscitados por via reflexa. Já os movimentos conjugados no plano frontal (dextro ou levoci- cloversão) são apenas originados de estímulos por via reflexa (por exemplo, na inclinação da cabeça para o ombro direito, tende a aparecer uma levocicloversão, embora não compensatória). Note-se que, com exceção dos movimentos versionais verticais em que ambos os olhos apresentam as mesmas duções (sursunversão, correspondendo à sursundução de cada olho; e deorsunversão, correspondendo à deorsundução de cada olho), as versões no plano horizontal e frontal se originam de duções com sentidos orbitários desiguais. Assim, a dextroversão (rotação binocular conjugada para a direita) é composta de abdução do olho direito (OD) e de adução do olho esquerdo (OE), enquanto a levoversão corresponde à adução do OD e abdução do OE. A dextrocicloversão depende da exciclodução do OD e da inciclodução do OE; e a levocicloversão é formada pela inciclodução do OD e exciclodução do OE.

\section{b) Vergências}

Chamam-se vergências, ou movimentos binoculares disjuntivos, os que se dão em sentidos orbitários antagônicos, isto é, para o lado nasal (adução) pelo OD e pelo OE (convergência), para o lado temporal (abdução) pelos dois olhos (divergência). A sursundução do OD e a deorsundução do OE é chamada divergência vertical D/E (ou "positiva"), enquanto a deorsundução do OD e a sursundução do OE é denominada divergência vertical E/D (ou "negativa"). A exciclodução de cada olho é chamada exciclovergência e a inciclodução do OD e do OE, exciclovergência.

Porém, com exceção dessa nomenclatura classificatória, não há maior interesse sobre tais movimentos. De fato, com exceção da convergência, movimento produzido voluntariamente, ou despertado reflexamente (e.g., a convergência fusional) e para o qual existe um propósito natural (o direcionamento simultâneo dos eixos visuais para um objeto próximo), não há qualquer razão para que os outros sejam produzidos (a binocularidade seria rompida, aparecendo diplopia e confu- 
são). Certamente será possível observá-los em certas circunstâncias e ocasiões. Por exemplo: a exotropia intermitente é uma condição em que aparece uma divergência (real) a partir de um estado de paralelismo ocular. Mas isso não quer dizer, necessariamente, que exista um "centro" ativo para a divergência, ou que ela resulte de um mecanismo específico para produzi-la. Uma explicação pode ser a de que o estado de divergência seja o erro básico do sistema, compensado por uma convergência (dando então o paralelismo binocular), cujo relaxamento suscita o aparecimento da disfunção. Nesse caso, seria melhor falar-se numa "desconvergência"(2).

Uma divergência vertical, quando demonstrada, é descrita como "dissinergia vertical", admitindo-se o erro inervacional: em lugar do movimento binocular conjugado aparece, patologicamente, o disjuntivo.

\section{4) Núcleos oculomotores e inervação}

Um quarto dos doze pares de nervos cranianos é exclusivamente destinado a levar estímulos a músculos oculares.

a) Nervo oculomotor comum (III)

Aciona o reto medial (RM), o reto superior (RS), o reto inferior (RI) e o oblíquo inferior (OI), além do músculo levantador da pálpebra superior, o ciliar e o do esfínter da íris. No caso dos músculos oculares externos (MOE) a inervação do núcleo aos respectivos músculos é ipsilateral, embora ainda persista alguma controvérsia sobre o assunto.

b) Nervo troclear (IV)

Inerva exclusivamente o oblíquo superior (OS), contralateralmente.

c) Nervo abducente (oculomotor externo) (VI)

Inerva exclusivamente o reto lateral (RL), ipsilateralmente.

\section{FISIOLOGIA DA MUSCULATURA OCULAR EXTRÍNSECA}

\section{A) Atividade muscular: contração e relaxamento}

O resultado do estímulo neural chegado ao músculo ocular externo é um estado de atividade (também denominado tonicidade), que pode ser variado para mais ou para menos. $\mathrm{O}$ aumento da tonicidade muscular corresponde a um aumento da força do músculo e ocorre como contração; ao contrário, a tonicidade muscular pode se reduzir, significando uma diminuição da respectiva força presente e isso ocorre como relaxamento.

A resposta natural de um músculo isolado e livre de outras ações ao estímulo neural (ou a outro, direto, sobre o corpo muscular: elétrico, químico ou térmico) é o de sua redução de comprimento, num processo denominado contração isotônica ${ }^{(7)}$. De fato, a produção de força muscular é convertida em energia cinética (o encurtamento do próprio músculo), que pode se transmitir a estruturas vizinhas (produzindo, por exemplo, o movimento ocular de rotação). Se, entretanto, oferece-se resistência a tal encurtamento do músculo, contendo-o por uma força contrária à que se desenvolve internamente nele, o processo é o de uma contração isométrica (o comprimento do músculo permanece inalterado $)^{(7)}$. O fenômeno contrário, o de redução da atividade do músculo (por diminuição do estímulo inervacional) pode, também, ocorrer sem variação do comprimento de suas fibras (relaxamento isométrico) ou com aumento dele, quando distendido por forças oponentes (relaxamento isotônico) $)^{(7)}$.

\section{Lei de Sherrington ou da inervação recíproca}

Normalmente os músculos se distribuem pelo olho em pares: o dos retos horizontais (medial e lateral), o dos retos verticais (superior e inferior) e o dos oblíquos (superior e inferior), com posicionamentos em situações de simetria especular e possuindo ações equivalentes, geralmente (mas não obrigatoriamente, como se verá a seguir) opostas. Assim, quando um deles é acionado para contração, o músculo oponente de cada par é simultaneamente estimulado para se relaxar. Esse mecanismo de cada par muscular, em que um se contrai (chamado então agonista, do grego “agon”: luta, ação) e o outro se relaxa (o músculo antagonista), é governado pela lei da inervação recíproca, ou lei de Sherrington ${ }^{(3,5-6)}$ e constitui uma condição normalmente requerida para os movimentos oculares rotacionais. De fato, se os dois músculos desse par fossem simultaneamente estimulados para contração, elas darse-iam de modo isométrico, a força desenvolvida por um deles sendo neutralizada pela do outro, de modo que não resultasse uma rotação do olho. Ainda que uma resposta desse tipo possa ocorrer em condições normais (sendo a convergência assimétrica o exemplo clássico de tal fenômeno), a desobediência à lei de Sherrington é tipificada na síndrome de Duane.

\section{B) Rotações oculares}

\section{1) Posição primária do olhar}

As forças de contração e relaxamento geradas pela musculatura ocular extrínseca, aplicadas sobre a superfície do olho, cujos envoltórios e estruturas de sustentação acomodam-no na órbita, produzem-lhe rotações, isto é, movimentos em torno de um ponto fixo (o centro de rotação ocular). A direção e sentido com que tais forças são aplicadas vão definir a especificidade da rotação produzida. Para análise dessas condições, a noção preliminarmente necessária é a do sistema referencial; no caso, o conjunto de eixos ortogonais situados imaginariamente sobre a órbita (o sistema de eixos orbitários, fixos), com a conseqüente definição de planos, arbitrariamente dispostos como um horizontal e dois verticais (o sagital e o frontal).

Ainda que a disposição horizontal e vertical desses planos e eixos orbitários possa ser objetivamente composta (em função da linha de ação gravitacional da Terra naquele local, para definir o eixo vertical do sistema; e dos outros dois eixos horizontais, ortogonais entre si e perpendiculares ao primeiro), sua localização exata na órbita não tem parâmetros seguramente estabelecidos ou convencionados. Em outras palavras, ainda que seja fácil estabelecer de modo objetivo um sistema referencial tridimensional de eixos e planos, a localiza- 
ção da órbita nele (ou vice-versa, o que é equivalente) torna-se matéria controversa. Em geral, tomam-se intuitivamente (já que faltam convenções pré-estabelecidas), linhas imaginárias entre pontos anatômicos da cabeça ou face (considerando-se, pois, as duas órbitas) que possam ser coincidentes às linhas horizontais e, ou verticais objetivas e que sirvam, pois, para situar a cabeça (e conseqüentemente as órbitas) nesse referencial fixo do espaço. A dificuldade, entretanto, é a de que a anatomia da cabeça e a da face, com que pontos de convenção posicional possam ser propostos apresenta-se variável (uma linha considerada para caracterizar a situação da cabeça no “espaço objetivo” pode servir para uma pessoa, mas não para outra) e assimétrica (não se encontra a esperada relação geométrica entre linhas que devessem ser paralelas ou, então, perpendiculares entre si).

A segunda noção é a do "objeto" cujo movimento deve ser avaliado em tal sistema referencial e a do parâmetro utilizado para a medida (isto é, o olho e o ângulo de rotação), o que suscita a elaboração de um novo sistema referencial, o dos eixos oculares, cujos movimentos (rotacionais) relativamente ao primeiro serão considerados. A dificuldade, agora, torna-se ainda maior, pois o posicionamento desse conjunto referencial no espaço torna-se inteiramente dependente, na prática, do "objeto" (olho) cuja posição se quer objetivar. Um dos eixos é o visual, ou de fixação, cuja localização num plano horizontal objetivo depende da integridade da função visual discriminativa (foveal).

Mesmo que a fixação visual do objeto seja então garantida, o exato posicionamento desse eixo no plano horizontal depende do nivelamento entre o ponto de fixação e a fóvea, uma condição operacionalmente muito complicada e, praticamente, conseguida apenas por aproximação. Entretanto, supondo-se que esse eixo possa ser precisamente ajustado a um plano horizontal, restaria ainda, finalmente, obter-se a coincidência entre o sistema referencial fixo, o dos eixos orbitários (dos quais apenas o vertical tem sua posição objetivamente conhecida) e o móvel, dos eixos oculares (dos quais apenas o visual teria sua situação estabelecida). Tal situação de coincidência dos eixos fixos (orbitários) e móveis (oculares) é a que define a chamada posição primária do olhar, o ponto zero das medidas de posição e deslocamento do olho, a partir da qual elas deverão ser referidas ${ }^{(2,8)}$.

Ora, o posicionamento do eixo ocular vertical ou do horizontal, transversal (látero-medial) deve ser necessariamente informado pelo sujeito da observação, já que não há qualquer indício anatômico da retina ou de outras partes do olho, concreto e seguro, com o qual se possa garantir, objetivamente, o posicionamento do olho no espaço. Essa condição torna o conceito de posição primária do olhar de obtenção meramente subjetiva e as tentativas de operacionalização objetiva dela inteiramente desprovidas de significado. Aliás, mesmo quando a informação dos eixos oculares vertical e, ou transversal puder ser fidedignamente alcançada, a coincidência dos sistemas de eixos oculares (móveis) e fixos (orbitários) torna-se problemática, pela já mencionada falta de padrões definidos para estes últimos. Desse modo, a conceituação do que seja posição primária do olhar acaba num critério operacional muito vago: é a condição do "olhar em frente com a cabeça ereta".

\section{2) Referenciais das rotações}

Um outro problema suscitado pela existência de dois sistemas referenciais (o orbitário, de eixos fixos; e o ocular, de eixos móveis, com o olho) é a possibilidade de se definir as rotações em cada um dos três planos fundamentais (as horizontais, as verticais e as torcionais) de modo independente e com diversas combinações. Apenas considerando-se as rotações horizontais e verticais, são quatro as possibilidades ${ }^{(9)}$ :

a) Medidas das rotações horizontais e verticais, ambas, em torno de eixos fixos (orbitários);

b) Medidas das rotações horizontais, em torno de um eixo (vertical) fixo e das verticais em torno de um transversal do olho, móvel com ele;

c) Medidas das rotações verticais em torno de um eixo (transversal) fixo e das horizontais em torno de um vertical do olho (móvel com ele);

d) Medidas das rotações horizontais e verticais, ambas, em torno de eixos oculares (móveis).

Obviamente, falar em uma "rotação vertical de $30^{\circ}$ combinada a uma horizontal de $20^{\circ}$ " sem definir a convenção escolhida para as medições, é absolutamente vago e sem qualquer significado já que, com a indicação meramente quantitativa dos movimentos realizados (sem caracterizá-los nos referenciais), são quatro as possibilidades de posicionamento ocular no espaço. Ou, inversamente, uma posição ocular pode ser definida por quatro diferentes combinações entre valores de rotações horizontais e verticais.

A combinação "b" é uma das mais usadas, correspondendo ao chamado sistema de Fick. Provavelmente por analogia a como são descritos ângulos sobre esferas que representam a Terra, isto é, com linhas paralelas ao equador (linhas de latitudes) e com linhas convergentes nos pólos (linhas de longitudes), respectivamente linhas "horizontais" (latitudes) traçadas em torno de um eixo "vertical" fixo (o que vai de um pólo a outro) e linhas "verticais" (longitudes) sempre feitas em torno de um eixo "horizontal" móvel (Figura 4 b), a combinação acima referida ("b") é mais comumente assimilada. Não há, entretanto, uma convenção internacional firmemente estabelecida sobre o assunto. A combinação “c”, por exemplo, é conhecida como sistema de Helmholtz, enquanto a "a" dá sustentação a como as rotações são exprimidas numa tela de Hess-Lancaster. Obviamente, se forem também consideradas as possibilidades de medida das torções (em torno de um eixo orbitário, fixo; ou em torno de um ocular, o que, todavia, seria mais lógico) o problema se torna ainda mais complexo ${ }^{(9)}$.

De qualquer modo, a falta de padronização das medidas rotacionais representa uma lacuna desconcertante e incompreensível na ciência da oculomotricidade. 


\section{C) Ações musculares rotacionais}

\section{1) Plano de ação muscular}

Para análise das rotações produzidas por um músculo ocular, a noção preliminar é a do plano de ação muscular, cuja determinação resulta da localização de três pontos (pelos quais deve passar esse plano imaginário): o centro de rotação ocular (comum a todo e qualquer plano de ação muscular) e os específicos a cada músculo: o "ponto" de inserção ocular do músculo e o de sua origem orbitária. Efetivamente, "pontos" de inserção (escleral) e de origem do músculo são simplificações geométricas, representando a localização "média" do conjunto de suas fibras, que se distribuem anatomicamente por amplitudes maiores: músculos inserem-se no olho por faixas relativamente extensas (cerca de 10 ou mais milímetros, numa superfície esférica cujo raio de curvatura normal é de pouco mais de $12 \mathrm{~mm}$ ) e com largura apreciável macroscopicamente (pelo menos um milímetro); e na órbita por volumes não desprezíveis.

Do ponto de vista estritamente geométrico, o "plano" de ação muscular é o que contém a "linha" de ação muscular, a distância mais curta entre o "ponto" de inserção ocular e o de origem orbitária do músculo. De fato, na superfície de uma esfera, a distância mais curta entre dois pontos é a de um arco do maior círculo que passe por eles (o maior círculo equivale a um equador da esfera). Assim, em outras palavras, pode-se dizer que o plano de ação muscular contém a linha de ação muscular; que passa pelo ponto de inserção ocular do músculo (I) e pelo de sua origem orbitária (O), tendo entre eles um ponto $\mathrm{F}$, o de inserção fisiológica do músculo. Então, a linha

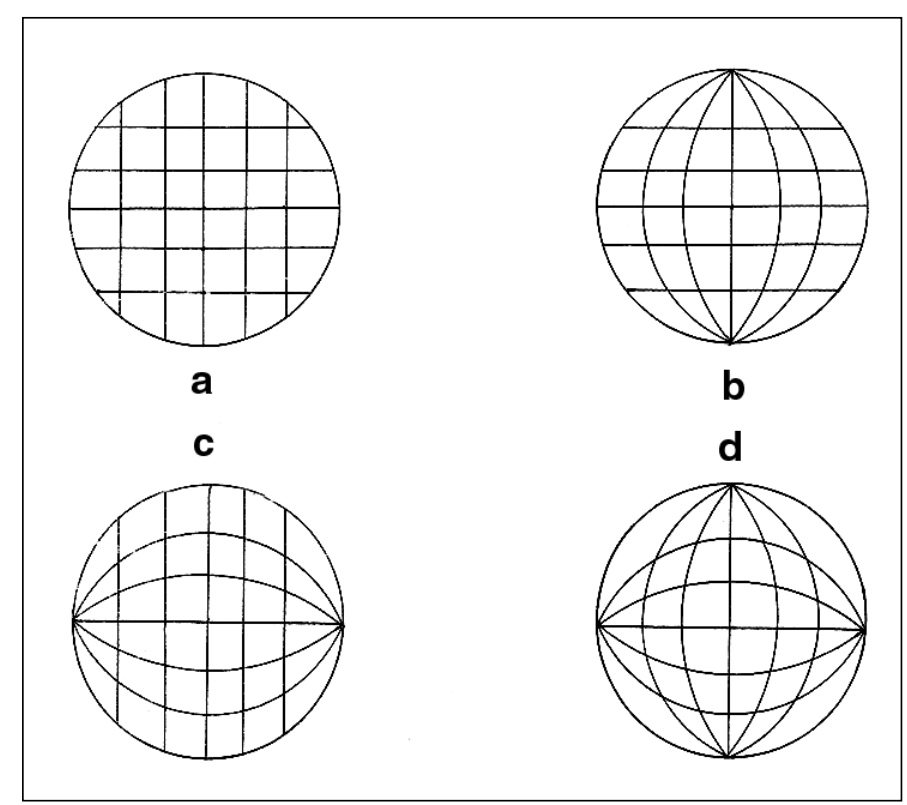

Figura 4 - Linhas referenciais para medidas de posições numa esfera, em projeções planas a partir de seu centro, em sistemas de coordenadas consideradas em relação a um eixo horizontal e um vertical, respectivamente: a) fixo e fixo; b) móvel e fixo (sistema de Fick); c) fixo e móvel (sistema de Helmholtz); d) móvel e móvel
$\overline{\mathrm{IF}}$ será sempre uma curva de círculo máximo, recebendo o nome especial de "arco de contato" (do músculo à esclera). A linha, $\overline{\mathrm{FO}}$ teoricamente, num sistema simplificado, será sempre uma reta, tangente à superfície ocular no ponto $\mathrm{F}$.

\section{2) Distribuição anatômica dos músculos}

Em outras palavras, a posição do músculo na órbita, sua anatomia topográfica, determina-lhe as funções. Dos seis músculos externos de cada olho, cinco originam-se do fundo da órbita, formando em seu conjunto o anel de Zinn: os retos medial (RM), lateral (RL), superior (RS) e inferior (RI), além do oblíquo superior $(\mathrm{OS})^{(3)}$. Mas enquanto os primeiros estendem-se diretamente ao olho (daí a denominação "retos"), o OS direciona-se ao canto súpero-interno (medial) da respectiva órbita de onde se reflete numa espécie de polia, a tróclea ("trokhilia", roldana, em grego), daí retornando ("para trás") para então prender-se ao olho. A origem funcional do OS é, então, a tróclea. O sexto músculo, o oblíquo inferior (OI) tem origem anatômica (e funcional) na porção ínfero-anterior da parede medial da órbita.

No olho, os quatro músculos retos inserem-se de modo mais ou menos regular e simétrico em torno do limbo: o RM do lado medial (ou nasal) a cerca de $5,5 \mathrm{~mm}$ dele; o RI do lado inferior, a cerca de $6,5 \mathrm{~mm}$ dele (geralmente de modo oblíquo, estendendo-se, aproximadamente, de $5,5 \mathrm{~mm}$ do lado medial a uns $8 \mathrm{~mm}$ do lado temporal); o RL do lado lateral (ou temporal) a cerca de 6,5 a $7 \mathrm{~mm}$; e finalmente o RS do lado superior, a uns 7 ou $8 \mathrm{~mm}$ do limbo (também obliquamente: de 6,5 a $7 \mathrm{~mm}$ do lado nasal e de 9 a $11 \mathrm{~mm}$ do lado temporal) ${ }^{(2-5)}$. (O progressivo distanciamento das inserções dos músculos retos ao limbo, do RM ao RS, descreve uma linha imaginária em torno do limbo - chamada espiral de Tillaux.) As inserções dos músculos retos estendem-se, externamente, por sobre a região que, internamente, corresponde à "ora serrata". O OS passa por baixo do RS e insere-se por um delicado tendão no octante ocular posterior, superior e lateral. O OI passa inferiormente ao RI e com um trajeto aproximadamente paralelo ao do OS insere-se no octante ocular posterior, inferior e lateral. Às inserções dos oblíquos estão próximas as saídas das veias vorticosas (principalmente a súpero-medial, perto do lado medial da inserção do OS e a ínfero-lateral, praticamente junto à inserção lateral do OI). O nervo óptico não fica, também, muito distante das extremidades mediais das inserções do OS e do OI (principalmente deste; da qual extremidade também estão próximas artérias ciliares posteriores longas e nervos ciliares).

\section{3) Ações dos músculos com o olho em posição primária}

Dessa distribuição anatômica dos músculos oculares externos resulta uma ação específica de cada um. Numa concepção geométrica simples, a ação isolada de cada músculo sobre o olho situado em posição primária é, classicamente:

a) Para o RM: adução;

b) Para o RL: abdução;

c) Para o RS: sursundução, adução e inciclodução; 
d) Para o RI: deorsundução, adução e exciclodução;

e) Para o OI: exciclodução, sursundução e abdução;

f) Para o OS: inciclodução, deorsundução e abdução.

Os músculos podem, então, ser divididos em pares, como o dos retos horizontais, responsáveis pelas ações horizontais; o dos retos verticais, responsáveis, principalmente, pelas ações sobre o plano sagital (sursundução e deorsundução) mas (secundariamente) sinergistas da adução e com ações torcionais opostas (embora discretas). E o dos oblíquos, responsáveis, principalmente, pelas ciclotorções (e com ações horizontais tão débeis que se chega, inclusive, a cálculos em que a ação do OI poderia ser até de abdução) ${ }^{(10)}$. De qualquer modo, embora muito comumente usada, é dúbia a atribuição de sinergismo entre retos verticais e oblíquos: o OS pode ser considerado sinergista do RI para ações de deorsundução, mas é antagonista dele para ações torcionais e horizontais, assim como, para elas, o OI seria antagonista do RS, embora tais músculos possam ser ditos sinergistas para a ação vertical (sursundução).

\section{4) Ações dos músculos em outras posições do olhar}

$\mathrm{O}$ conhecimento de como se fundamentam e calculam as ações de cada músculo com o olho situado em posição primária é importante pois dele também deriva o princípio de determinação das respectivas funções musculares em outras circunstâncias do posicionamento ocular. Pela mesma razão, as ações musculares na posição primária do olhar são meramente descritivas do que ocorre nessa condição específica, não servindo para generalizações. Realmente, pela mudança das relações referenciais do posicionamento da inserção ocular do músculo (e, pois, também de sua inserção fisiológica) ocorridas por uma rotação do olho, novos cálculos devem ser feitos para a nova situação.

Assim, por exemplo, as ações verticais dos retos verticais tornam-se privilegiadas à medida que o olho abduz, enquanto as outras ações (horizontais e torcionais) diminuem ${ }^{(3)}$. Chegase a uma posição de abdução (cerca de $25^{\circ}$ ) em que o alinhamento desses músculos com o centro de rotação ocular (ou com o ponto de inserção fisiológica) e com a origem orbitária é tal que a ação vertical do músculo (sursundução para o RS, deorsundução para o RI) torna-se única, desaparecendo as que a complementavam. Em abduções ainda maiores, a ação vertical de cada um desses músculos mantém o sentido, mas volta a se reduzir, já que parte da força desenvolvida é agora distribuida pelos planos sagital e torcional; porém, agora, elas se invertem (relativamente às que apareciam na posição primária): o RS passa a abdutor e exciclodutor, enquanto o RI passa a abdutor e inciclodutor. Por outro lado, para os oblíquos, a ação vertical deles se reduz em abdução, enquanto aumenta a ação torcional e horizontal (abdução) deles, dando-se o oposto na rotação de sentido contrário (adução): aumenta a ação vertical (tornando-se máxima em aduções acima de $50^{\circ}$ ), enquanto diminui a ação torcional; do ponto de vista horizontal os músculos passariam a contribuir para a adução. Já os retos horizontais passariam a elevadores em sursundução (o RM sendo também exciclodutor e o RL inciclodutor), invertendose suas ações (verticais e torcionais) em deorsundução.

\section{5) Efeito de fáscias e membranas intermusculares}

Todas essas condições e resultados são, entretanto, baseados na concepção de que os músculos possam deslizar livremente sobre a superfície escleral, uma proposição teórica sem comprovação. Ao contrário, os músculos estão encapsulados por membranas, que também envolvem o olho e ligam todos num conjunto em que as posições relativas de cada um são quase que absolutamente conservadas, a despeito de rotações oculares. Assim, embora as coordenadas da inserção escleral do músculo mudem no referencial orbitário, em conseqüência de movimentos oculares realizados, a posição do músculo sobre o olho mantém-se praticamente inalterada relativamente a ele e à órbita. Fala-se desse ponto (mais ou menos fixo), em direção ao qual a aplicação da força desenvolvida se faz, como se fosse uma nova origem, perto do equador ocular: uma "polia" (P) na qual o músculo se reflete ${ }^{(11)}$. Em outras palavras: a linha $\overline{\mathrm{OP}}$ (da origem anatômica $\mathrm{O}$, à funcional $\mathrm{P}$ ) mantém-se como linha reta, enquanto a de $\mathrm{P}$ a I (inserção ocular do músculo) é a que confere a direção da força desenvolvida. Como a capa envoltória do olho e músculos dá a essas "polias" (os pontos $\mathrm{P}$ de cada músculo) uma localização próxima ao plano frontal do olho (para os músculos retos), resulta uma ação quase que constante de cada um e bem similar à da que se descreve para a posição primária do olhar.

É óbvio, entretanto, que quando as membranas intermusculares são seccionadas em técnicas cirúrgicas de correção de estrabismos, as concepções de "deslizamento" muscular sobre o olho devem voltar a ser consideradas ${ }^{(12)}$.

\section{6) A concepção moderna sobre as ações musculares}

Embora o RS seja o músculo mais importante na produção de uma sursundução pura, ele não é o único a ser acionado nessa circunstância. Na verdade, se ele fosse isoladamente estimulado, a sursundução seria também acompanhada de adução e inciclodução. Lembre-se, aliás, que (pela lei de Sherrington) quando um músculo se contrai, seu oponente (antagonista) direto, no caso o RI, se relaxa, liberando a sursundução, mas também abdução (que poderia, teoricamente, compensar a adução do RS) e inciclodução. Desse par muscular resultaria, pois, sursundução acompanhada de inciclodução. Assim, requerer-se-ia o concurso dos oblíquos para a produção de exciclodução compensatória: inervação para contração do OI (tido, aliás, como sinergista do RS na produção da elevação) e relaxamento do OS. Admitindo-se absoluta simetria anatômica dos componentes desses dois pares de músculos, dever-se-ia então concluir que a ação simultânea deles seria necessária para produção da sursundução pura. Se a sursundução fosse acompanhada de adução (ou de abdução), os músculos horizontais deveriam ser também acionados e uma complexa distribuição de estímulos inervacionais tornar- 
se-ia naturalmente exigida. Enfim, admite-se que para as rotações oculares (pelo menos para a maioria delas, às chamadas posições terciárias do olhar) todos os seis músculos de cada olho devem estar simultaneamente acionados, quer (uns) para contração, quer (outros) para relaxamento, sem o que o movimento não se faz normalmente.

\section{D) Lei de Hering}

Uma das condições clínicas mais importantes para o estabelecimento diagnóstico das disfunções musculares tem por base a lei de Hering. Ao contrário da de Sherrington (das inervações recíprocas, ou inversas, entre um músculo e seu antagonista direto, no mesmo olho), a de Hering é a das inervações iguais, para um músculo e seu conjugado (isto é, para o par de músculos acionados numa versão) ${ }^{(4-5)}$. Hodiernamente não se menciona mais "inervações" iguais, mas "inervações para rotações" iguais, uma sutil diferença, devida ao fato de que o que o sistema nervoso pretende é, justamente, rotações iguais (mesmo que, para músculos desiguais, sejam necessários estímulos inervacionais diferentes $)^{(3)}$.

A figura 5 ilustra, esquematicamente, o comportamento inervacional dos pares de músculos horizontais (RME e RLE para o olho esquerdo, RMD e RLD para o direito), conforme tonicidades musculares (representadas pela letra A) e forças passivas de estruturas perioculares (representadas pela letra P), sempre equilibradas (A e P são tomadas, simplificada- mente, como equivalentes) em cada uma das posições oculares de levo ou dextroversão.

\section{E) Posições diagnósticas}

Um dos conceitos clínicos mais importantes é o das posições diagnósticas, aquelas nas quais se evidenciam as falências principais de cada um dos seis músculos oculares externos, já que, como mencionado, todos eles, de um modo ou de outro, acabam sendo importantes na maioria dos movimentos oculares. O grupo mais simples é o dos retos horizontais, tomado então inicialmente para exemplificação.

Suponha-se uma paresia de RLE, em que a atividade muscular desse músculo tenha sido reduzida pela metade. $\mathrm{Na}$ fixação do OD para uma dada posição (figura 6, mas tome-se como base de normalidade a figura 5) a redução de $\mathrm{A}$ à metade dos valores normais é explícita; na fixação do OE, as respostas posicionais requeridas podem ser obtidas mas, para que isso ocorra, o dobro da inervação deve ser enviada ao músculo (RLE); decorrentemente, o dobro da inervação (e, daí, o dobro da atividade) aparece como resposta do RMD.

Duas conseqüências podem ser facilmente observadas na figura 6:

a) O desvio é maior no sentido da ação do músculo afetado (levoversão, RLE) tanto na FOD como na FOE.

b) Em cada direção do olhar o desvio é sempre maior na fixação do olho que contém o músculo afetado (OE, RLE).

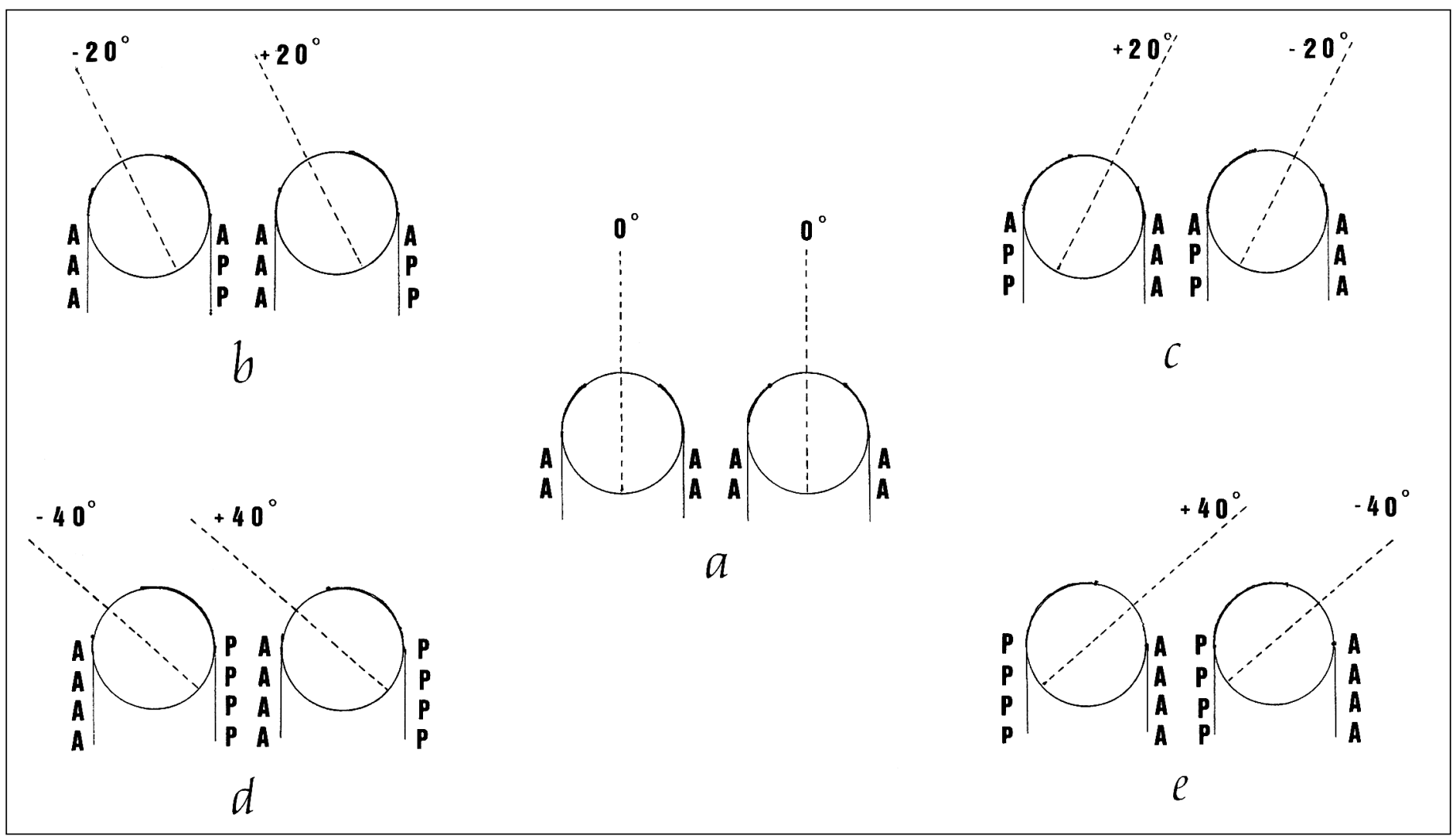

Figura 5 - Distribuição esquemática de tonicidades musculares (A) e funções passivas (P) em posição oculares: a) primária; b) levoversão de $20^{\circ}$, c) dextroversão de $20^{\circ}$; d) levoversão de $40^{\circ}$; e) dextroversão de $40^{\circ}$ 


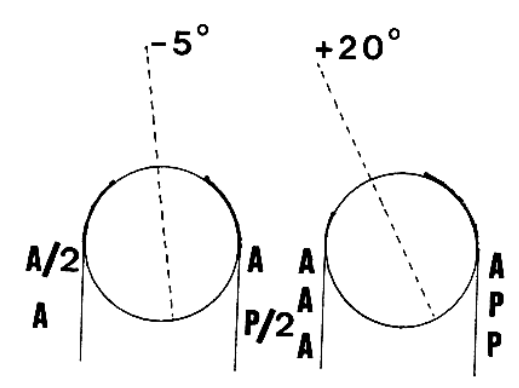

a

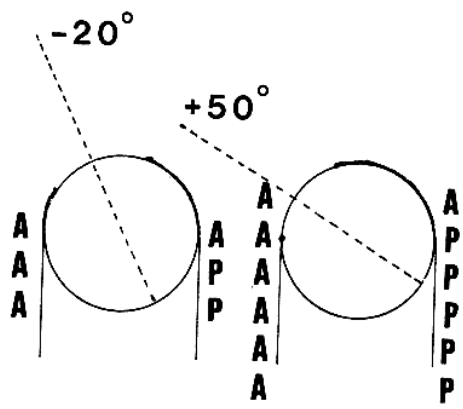

d

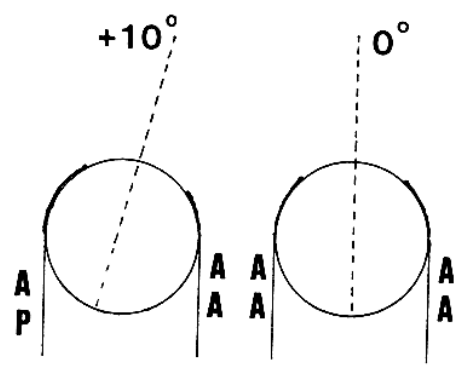

b
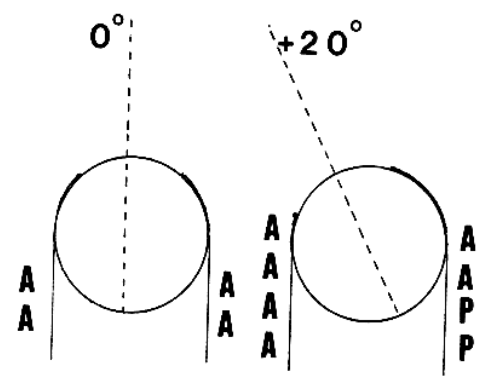

e

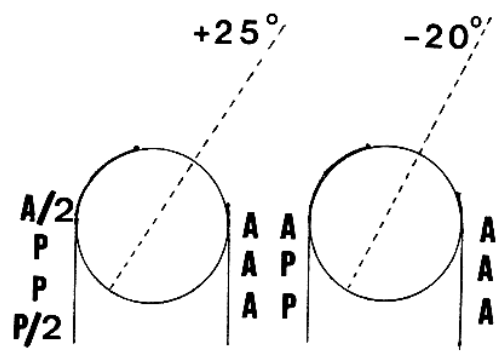

C

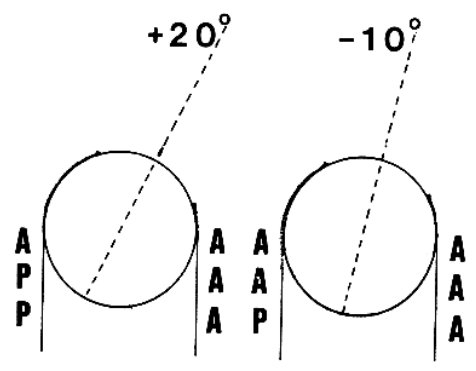

f

Figura 6 - Posições oculares na fixação pelo olho direito (acima) e na pelo olho esquerdo (abaixo), em levoversão (à esquerda), em frente (no meio) e em dextroversão (à direta), num caso de paresia de RLE

Obviamente, duas outras, complementares e opostas poderiam, igualmente, ser válidas:

c) O desvio é menor no sentido oposto (dextroversão) ao da ação do músculo afetado (RLE) tanto na FOD como na FOE.

d) Em cada direção do olhar o desvio é sempre menor na fixação do olho que não contém o músculo afetado (OD). Ora, na verdade, as duas primeiras e as duas últimas poderiam ser condensadas respectivamente em:

e) O desvio é maior no sentido da ação do músculo afetado e na fixação do olho que o contém (levoversão, FOE: RLE).

f) O desvio é menor no sentido oposto ao da ação do músculo afetado e quando fixa o olho são (dextroversão, FOD: RLD). Mas a situação de "dextroversão na FOD" (o menor desvio quando o músculo parético é o RLE) é, precisamente, a de maior desvio quando o músculo parético é o RLD. E, vice-versa (Tabela 1). Dão-se, assim, as condições comparativas para quando, num caso de esotropia, com suspeita sobre se o músculo parético é o RLE ou o RLD, o diagnóstico deve ser feito.

Tratando-se de uma exotropia, com suspeita de hipofunção primária do RMD ou do RME, as posições comparativas são as de dextroversão na FOE (maior desvio se o músculo afetado for o RME, menor desvio se for o RMD) e de levoversão na FOD (maior desvio se o músculo afetado for o RMD, menor desvio se for o RME).

No caso de músculos retos verticais, igual princípio pode ser aplicado. Se o desvio for D/E (olho direito desviado para cima, ou o esquerdo para baixo), com suspeita de hipofunção primária do RID ou do RSE, a posição de maior desvio se o músculo parético for o RID é no olhar para baixo, na FOD (justamente a de menor desvio se a paresia for do RSE), enquanto a de menor desvio é no olhar para cima, na FOE (justamente a de maior desvio na paresia do RSE).

Finalmente, no caso de oblíquos, o mais indicado seria o estudo da ação principal deles, a torção, cujas observações não só se tornam bem mais difíceis, como as medidas dos desvios são inviabilizadas com os procedimentos tradicionais de exame (uso de prismas). Parte-se, então, para a observação de suas ações secundárias, mostrando desvios horizontais e, ou verticais, também presentes quando os oblíquos estão afetados.

Assim, por exemplo, a hipofunção de ambos oblíquos superiores (e, ou hiperfunção dos oblíquos inferiores) é, geralmente, causadora de uma variação em "V" do desvio horizontal (acentuação do esodesvio no olhar para baixo e sua redução no olhar para cima; ou redução do exodesvio no olhar para baixo e sua acentuação no olhar para cima), enquanto a hipofunção dos oblíquos inferiores (e, ou hiperfunção dos oblíquos superiores) vem, geralmente, com uma variação em "A" do desvio horizontal (acentuação do esodesvio no olhar para cima e sua redução no olhar para baixo; ou redução do exodesvio no olhar para cima 


\begin{tabular}{|llll|}
\hline \multicolumn{4}{c}{ Tabela 1. Condições de desvio máximo e mínimo para cada músculo ocular externo, primariamente hipofuncionante } \\
Desvio & Par & Maior desvio & Menor desvio \\
Eso & RLD & Dextroversão, FOD & Levoversão, FOE \\
& RLE & Levoversão, FOE & Dextroversão, FOD \\
Exo & RMD & Levoversão, FOD & Dextroversão, FOE \\
& RME & Dextroversão, FOE & Levoversão, FOD \\
E/D & RSD & Supradextroversão, FOD & Infralevoversão, FOE \\
& RIE & Infralevoversão, FOE & Supradextroversão, FOD \\
& OID & Supralevoversão, FOD & Infradextroversão, FOE \\
& OSE & Infradextroversão, FOE & Supralevoversão, FOD \\
R/E & RID & Infradextroversão, FOD & Supralevoversão, FOE \\
& RSE & Supralevoversão, FOE & Infradextroversão, FOD \\
& OSD & Infralevoversão, FOD & Supradextroversão, FOE \\
& OIE & Supradextroversão, FOE & Infralevoversão, FOD \\
\hline
\end{tabular}

e sua acentuação no para baixo). Todavia quando, num desvio ciclovertical, aparece hipofunção de (por exemplo) um OSE (e hiperfunção secundária do OIE) há, também, hipofunção do OID (e hiperfunção secundária do OSD), ou seja, disfunções musculares de conseqüências opostas para a produção de variações em "V" e "A", respectivamente.

Costuma-se, então, usar para os oblíquos uma condição similar à que se aplica para o diagnóstico de hipofunção primária de um reto vertical: o exame dos desvios verticais. O produzido pelo OSD teria seu maior desvio no olhar para baixo na FOD e o menor no olhar para cima, na FOE (condição de maior desvio quando o músculo afetado é o OIE). Essa condição, entretanto, é similar à da distinção do par RID e RSE, o que se torna inconveniente, posto que num desvio vertical (por exemplo, D/E) maior numa das versões (por exemplo, no olhar para baixo), restariam, sempre, dois músculos como seus potenciais causadores primários (no caso, o RID e o OSD). Para diferenciá-las, usa-se a variabilidade da atuação vertical desses músculos em adução e abdução: retos verticais são mais efetivos em abdução que em adução (logo, um desvio vertical causado por um RSE é maior em levo que em dextroversão) enquanto que os oblíquos apresentam comportamento oposto (um desvio vertical causado por um OIE é maior em dextro que em levoversão). A tabela 1 mostra, então, as definições de pareamentos diagnósticos e as condições de posição ocular e fixação para estudar a função de cada dupla muscular.

\section{1) Efeito da manobra de inclinação da cabeça}

Desde há muito conhece-se o efeito da inclinação da cabeça na mudança de um desvio vertical, principalmente quando um oblíquo superior é o músculo primariamente hipofuncionante. $\mathrm{O}$ desvio vertical (por exemplo, D/E) então se acentua quando a cabeça é inclinada sobre o ombro do lado do olho "mais alto" (no caso, o ombro D) e se reduz na inclinação da cabeça para o lado contrário.

Essa variação é atribuida ao fato de que com a inclinação da cabeça ocorre uma estimulação labiríntica tendente a, reflexamente, produzir uma torção "compensatória". Na verdade, a torção ocular é apenas parcial (normalmente cerca de 10\% da angulação dada à cabeça) mas ocorre efetivamente no sentido de reduzir a inclinação do meridiano vertical da retina relativamente à gravidade. Por exemplo, na inclinação da cabeça para a direita, há um estímulo para a inciclotorção do OD e para uma exciclotorção do OE (Tabela 2).

Essa manobra da inclinação de cabeça para cada um dos lado (manobra de Bielschowsky) foi então proposta como recurso de diferenciação diagnóstica entre músculos cicloverticais, para apontar qual seria o primariamente hipofuncionante num desvio vertical, incorporando-se ao "teste de três passos" de Parks ${ }^{(13)}$. Assim, por exemplo, num desvio D/E, em que os músculos teoricamente hipofuncionantes são RID, OSD, OIE e RSE, o desvio na inclinação da cabeça para a direita ficaria atribuido à falência do OSD ou do OIE enquanto o na inclinação para a esquerda dever-se-ia ao RID ou ao RSE. A falha dessa proposição, aliás, comprovada por várias publicações ${ }^{(14-16)}$, tem explicação em pelo menos três elementos, principais:

a) A comparação se faz entre uma inclinação na qual o desvio vertical seria primariamente produzido pela hipofunção de um dos oblíquos (e.g., OSD e, ou OIE) contra outra em que o desvio vertical seria inicialmente produzido por um dos retos verticais (e.g., RID e, ou RSE). Ora, sabe-se que estes (retos verticais) são bem mais atuantes no plano sagital (produção de rotações e desvios verticais) que os primeiros (oblíquos), o que torna desaconselhável a comparação destinada a diferenciar efeitos de músculos de ação muito discrepantes (isto é, já naturalmente diferentes).

b) O desvio é medido num olho enquanto o outro (sobre o qual toda inervação é comandada) mantém sua fixação "em frente", isto é, numa posição ocular em que os músculos,

$\begin{aligned} & \text { Tabela 2. Ciclotorção ocular suscitada e músculos que a produzem } \\
& \text { (em cada olho), nas inclinações de cabeça para os lados (D e E) }\end{aligned}$
\begin{tabular}{lll} 
Olho & \multicolumn{2}{c}{ Inclinação } \\
D & Inciclotorção (OSD, RSD) & Exciclotorção (OID, RID) \\
E & Exciclotorção (OIE, RIE) & Inciclotorção (OSE, RSE)
\end{tabular}




\begin{tabular}{|l}
$\begin{array}{l}\text { Tabela 3. Desvios verticais (a...d) em função da inclinação de } \\
\text { cabeça e da fixação ocular } \\
\text { Inclinação }\end{array}$ \\
$\begin{array}{lcc}\text { Fixação } & \text { D } & \text { E } \\
\text { FOD } & \text { a } & \text { b } \\
\text { FOE } & c & d \\
\text { Possibilidades: } a>b>c>d \\
\text { ou } a>c>b>d\end{array}$ \\
\hline
\end{tabular}

tanto os oblíquos quanto os retos verticais (e horizontais) são pouco acionados para suas ações. Em outras palavras, a posição escolhida não é a mais adequada para distinção de possíveis deficiências musculares.

c) A proposição não menciona a necessidade de se definir com qual olho a fixação ao objeto é dirigida, o que constitui uma flagrante falha de semiologia. Obviamente, tanto numa inclinação quanto em outra, há a possibilidade de que diferentes desvios sejam constatados, em função do olho fixador. A tabela 3 mostra quatro medidas possíveis para um desvio vertical (a...d). Supondo-se que o maior seja a e que o menor seja d, há a possibilidade de que a progressão seja $a>b>c>d$ ou $a>c>b>d$, ou seja, o desvio que seria detectado como maior (a) numa das inclinações (para a D, na FOD) quando comparado ao da outra (b ou d) pode vir a ser tomado como menor $(\mathrm{c}<$ b) dependendo de se fixações forem trocadas.

Ora, não são apenas os oblíquos superiores os músculos estimulados. Ainda que com respostas menos pronunciadas, também os oblíquos inferiores e os retos verticais são acionados (Tabela 4).

Note-se que para um músculo (e.g., o OSD) a função maximamente suscitada (inciclotorção OD na inclinação para a $\mathrm{D}$, na FOD, para que ocorra o maior desvio) contrapõe-se à ação oposta (exciclotorção OD e inciclotorção OE) em que ocorre o menor desvio (na inclinação para a E, na FOE), justamente aquela em que aparece o maior desvio quando o músculo hipofuncionante é o RSE. Nesse caso, portanto, as oposições se dão entre o OS de um lado e o RS contralateral, entre o RI de um lado e o OI contralateral ${ }^{(17-18)}$.

\section{ACOMODAÇÃOECONVERGÊNCIA}

\section{A) A relação sincinética}

A acomodação é a função de ajustamento dióptrico pelo sistema óptico ocular, pelo qual o seu poder focal aumenta (fazendo, pois, com que o plano focal imagem do olho seja anteriorizado), por aumento da refringência do cristalino. Esse aumento, por sua vez, é produzido por maior convexidade das faces do cristalino (principalmente a anterior), atribuida a um relaxamento da zônula, por sua vez garantido pela contração do músculo (esfínter) ciliar. Esse mecanismo explicativo é o que corresponde à teoria de Helmholtz, elaborada em 1855 e só recentemente contestada por uma outra hipótese, a de Schachar e colaboradores ${ }^{(19-21)}$, cuja comprovação, entretanto, não resistiu a estudos experimentais ${ }^{(22-25)}$. Em outras palavras: continua, agora ainda mais fortalecida, a teoria clássica sobre o mecanismo da acomodação. Nela, também se admite que ocorra uma pequena anteriorização de todo o cristalino (o que, de certo modo, ajuda a anteriorizar o plano focal imagem do sistema óptico ocular). A acomodação é importante para que as imagens cujas formações seriam "além" da retina (o que ocorre para objetos muito distantes, em olhos com hipermetropia, ou para objetos próximos, em emétropes) possam ser aproximadas e, ou trazidas ao plano dela, garantindo a boa discriminação visual dos respectivos objetos.

A convergência é a função pela qual os dois retos mediais se contraem, ajustando o direcionamento dos eixos visuais a um objeto próximo.

Acomodação e convergência são mediadas por impulsos inervacionais conduzidos pelo par de nervos oculomotores comuns (III). Apesar de as respostas aos estímulos de cada uma dessas funções não serem proporcionalmente relacionadas (como se verá, em sequiência), a associação entre elas é indiscutível, constituindo uma sincinesia (do grego "syn", união, associação; "kynesis", movimento). Quando uma variação de acomodação (A) é suscitada por um estímulo, dá-se uma resposta não só dela como, automaticamente, também da convergência. À convergência assim produzida dá-se o nome convergência acomodativa $\left(\mathrm{C}_{\mathrm{A}}\right)$.

\begin{tabular}{|c|c|c|c|}
\hline $\begin{array}{l}\text { Músculo } \\
\text { hipofuncionante }\end{array}$ & Desvio & $\begin{array}{c}\text { Fixação e lado da } \\
\text { inclinação de aumento }\end{array}$ & $\begin{array}{c}\text { Fixação e lado da } \\
\text { inclinação de redução }\end{array}$ \\
\hline OSD & $\mathrm{D} / \mathrm{E}$ & FOD, D (inciclotorção D) & FOE, E (exciclotorção D) \\
\hline OIE & $\mathrm{D} / \mathrm{E}$ & FOE, D (exciclotorção E) & FOD, E (inciclotorção E) \\
\hline RID & $\mathrm{D} / \mathrm{E}$ & FOD, E (exciclotorção D) & FOE, D (inciclotorção D) \\
\hline RSE & $\mathrm{D} / \mathrm{E}$ & FOE, E (inciclotorção E) & FOD, D (exciclotorção E) \\
\hline RSD & $E / D$ & FOD, D (inciclotorção D) & FOE, E (exciclotorção D) \\
\hline RIE & $E / D$ & FOE, D (exciclotorção E) & FOD, E (inciclotorção E) \\
\hline OID & $E / D$ & FOD, E (exciclotorção D) & FOE, D (inciclotorção D) \\
\hline OSE & $E / D$ & FOE, E (inciclotorção E) & FOD, D (exciclotorção E) \\
\hline
\end{tabular}


Essa variação da acomodação (A) é feita geralmente por seu aumento, isto é, reduzindo-se o poder óptico de um olho, ou dos dois, ou seja, produzindo-lhes, ou aumentando, uma "hipermetropização". Tal procedimento corresponde à anteposição de lentes diante de um olho ${ }^{(*)}$ ou de ambos (medindose, então, ao teste de cobertura e prismas, a variação do estado de equilíbrio oculomotor, $\Delta \mathrm{M})$ :

$$
\mathrm{C}_{\mathrm{A}}=\Delta \mathrm{M} / \mathrm{A}
$$

As lentes de "hipermetropização" tanto podem ser negativas, em míopes (tendo então valores acima dos da respectiva correção óptica normal dessa ametropia) e emétropes; ou até positivas, em hipermétropes (mas correspondendo a uma menor correção óptica dessa ametropia).

O contrário também é demonstrável: quando a convergência é requerida (por prismas de base temporal), aparece uma resposta acomodativa, a acomodação convergencial $\left(\mathrm{A}_{\mathrm{C}}\right)$. Mas enquanto o aumento de $1 \mathrm{D}$ na acomodação (A) suscita uma resposta convergencial (convergência acomodativa, $C_{A}$ ) de cerca de $4^{\Delta}$ (isto é $\mathrm{C}_{\mathrm{A}} / \mathrm{A}=4^{\Delta} / \mathrm{D}$ ), será preciso uma convergência (C) de umas $40^{\Delta}$ como estímulo, para que uma acomodação convergencial $\left(\mathrm{A}_{\mathrm{C}}\right)$ de aproximadamente $1 \mathrm{D}$ seja demonstrada (isto é $\mathrm{A}_{\mathrm{C}} / \mathrm{C} \cong 0,025 \mathrm{D} / \Delta$, cerca de dez vezes menos do que a recíproca da relação $\left.C_{A} / A\right)^{(26)}$.

Obviamente, então, o interesse prático da sincinesia é explorado no lado da relação $\mathrm{C}_{\mathrm{A}} / \mathrm{A}$, reduzindo-se a acomodação (com a prescrição de lentes positivas) para a redução de esodesvios; ou aumentando-se o estímulo à acomodação para a redução de exodesvios. Por outro lado, a correção cirúrgica de esotropias (redução de "convergência") ou exotropias (redução de "divergências"), mesmo as de grandes ângulos, não modifica substancialmente o estado acomodativo.

\section{B) Convergência proximal}

O método pelo qual se chega ao valor da relação $C_{A} / A$ por variação do poder dióptrico de lentes (aumento da acomodação por diminuição do valor das lentes positivas, ou por aumento relativo do das negativas; ou diminuição da acomodação por aumento de lentes positivas em fixações para perto) mas sempre a uma mesma distância ao ponto de fixação é denominado "do gradiente". Há uma outra forma de determinação da relação entre a convergência e a acomodação, chamada de "método das heteroforias", pela qual se considera o valor do desvio, sob dissociação (teste de cobertura, vidro de Maddox, etc.) na fixação para longe (L) à distância $\mathrm{d}_{\mathrm{L}}$ e na para perto $(\mathrm{P})$ à distância $\mathrm{d}_{\mathrm{P}}$. Também se considera o valor da distância entre os centros de rotações oculares (tomada como equivalente à distância inter-pupilar, i). O cálculo é dado por:

(*) Esse procedimento para suscitar a acomodação (lente negativa diante de um olho, para fixação de um objeto, enquanto no outro, ao qual se antepõe um anteparo, aparece "adução", isto é, convergência) é equivalente ao que foi usado por Johannes Mueller para demonstração da resposta convergencial ao estímulo acomodativo (mudança de fixação de um olho, de longe para perto, na mesma direção "em frente", com um anteparo diante do outro).

$$
\mathrm{C} / \mathrm{A}=\mathrm{i}+\left[(\mathrm{P}-\mathrm{L}) \mathrm{d}_{\mathrm{P}} \mathrm{d}_{\mathrm{L}}\right] /\left(\mathrm{d}_{\mathrm{L}}-\mathrm{d}_{\mathrm{P}}\right)
$$

Tomando-se $\mathrm{d}_{\mathrm{L}} \cong \infty$, resulta:

$$
\mathrm{C} / \mathrm{A}=\mathrm{i}+(\mathrm{P}-\mathrm{L}) \mathrm{d}_{\mathrm{P}}
$$

em que $\mathrm{P}$ e $\mathrm{L}$ devem aparecer em dioptrias-prismáticas, $\mathrm{d}_{\mathrm{p}}(\mathrm{a}$ distância na medida para perto) em metros e $\mathbf{i}$ em centímetros. $\mathrm{Na}$ verdade, o valor desse qüociente (C/A) é geralmente maior do que o da relação $C_{A} / A$ "pura" (tomada pelo método de gradiente), sendo a diferença entre eles interpretada como devida a uma "relação proximal", dependente da chamada "convergência proximal" $\left(\mathrm{C}_{\mathrm{P}}\right)$.

$$
\mathrm{i}+(\mathrm{P}-\mathrm{L}) \mathrm{d}_{\mathrm{P}}=\left(\mathrm{C}_{\mathrm{A}}+\mathrm{C}_{\mathrm{P}}\right) \mathrm{d}_{\mathrm{P}}=\mathrm{C}_{\mathrm{A}} / \mathrm{A}+\mathrm{C}_{\mathrm{P}} / \mathrm{D}
$$

\section{C) Unidades}

A unidade de acomodação é, sempre, a dioptria (esférica), equivalente à recíproca da distância (d) à qual se localiza o objeto de fixação, ou à recíproca da distância focal (f) do olho, ou sistema óptico:

$$
1 / \mathrm{d}=\mathrm{D}_{1} \text { ou } 1 / \mathrm{f}=\mathrm{D}_{2}
$$

A da convergência é, geralmente, a dioptria-prismática. Uma dioptria-prismática é a angulação formada pela separação de $1 \mathrm{~cm}$ entre dois pontos $(=\mathrm{BC})$ tomada a um metro de distância $(=\mathrm{AB})$.

Ângulos, por outro lado, são comumente medidos em graus ou radianos $\left(360^{\circ}=2 \pi \mathrm{rad}\right)$. As relações entre os valores de um ângulo a em graus, em dioptrias-prismáticas (P), ou radianos (y) é:

$$
\begin{aligned}
& \arctan \mathrm{a}=\overline{\mathrm{BC}} / \overline{\mathrm{AB}} \\
& 100 \overline{\mathrm{BC}} / \overline{\mathrm{AB}}=\mathrm{P} \therefore \mathrm{P}=100 \arctan \mathrm{a} \\
& \mathrm{y}=2 \pi \mathrm{a} / 360=0,01745 \mathrm{a}
\end{aligned}
$$

Também se usa o centrad $(=0,01 \mathrm{rad}$, o centésimo do radiano), de modo que (sendo $\left.y^{\prime}=y / 100\right)$

$$
\mathrm{y}^{\prime}=1,7455 \mathrm{a} \text { (centrads) }
$$

Aplica-se, ainda, como unidade de convergência, o conceito de "ângulo-métrico", avaliado, também, como o inverso da distância $\left(\mathrm{d}^{\prime}\right)$ do ponto de fixação à linha que une os centros de rotação oculares:

$$
1 \text { a.m. }=1 / \mathrm{d}^{\prime}
$$

Mas essa unidade, cuja vantagem seria a de ter equivalência (pelo menos aproximada) à da acomodação $(\mathrm{A}=1 / \mathrm{d})$ não é muito usada.

A convergência acomodativa $\left(\mathrm{C}_{\mathrm{A}}\right)$ ou a proximal $\left(\mathrm{C}_{\mathrm{P}}\right)$ são referidas em unidades de convergência (em geral, dioptriasprismáticas).

Para a relação $\mathrm{C}_{\mathrm{A}} / \mathrm{A}$ ou para a C/A, usa-se uma unidade de convergência (geralmente a dioptria-prismática), relacionada à de acomodação (dioptria "esférica").

Para a relação $\mathrm{C}_{\mathrm{P}} / \mathrm{D}$, também, a unidade comumente usada é a da dioptria-prismática / dioptria.

\section{ABSTRACT}

The paper starts from a schematic circuit establishing a relationship of the sensorial (visual, binocular) with the oculomotor systems, whose defects of their afferent or efferent path- 
ways, or of their interactions, explain the emergence of strabismus with its consequences. The foundations and referentials of ocular movements are then examined: the concepts of axes and planes, of the centers of mass and of rotation, of monocular displacements of translation and rotation, of binocular version and vergence displacements. The functions of centers of command for voluntary or reflex ocular movements are also presented, as well as the innervation of extrinsic ocular muscles. In a second part (physiology of the extrinsic ocular muscles), activities of contraction or relaxation and the importance of Sherrington's law are commented. The concepts of primary position of gaze and of the referentials for rotations are retaken leading to the diversity of the several systems of measurements. There follows analysis of the rotational actions of the ocular muscles, based on the so-called planes of muscular actions and on the anatomic distribution of the muscles, leading to the results in primary position of gaze and others. The effects of fascias and intermuscular membranes are also commented. Conclusively the modern concept of the muscular actions is presented (simultaneous actions of all muscles in each ocular position). Based on the conditions of Hering's law the concept of positions for the diagnosis of the oculomotor disfunctions, which differs from the classical one is developed: the muscles are considered in pairs, according to their predominant actions - horizontal (horizontal recti), vertical (vertical recti) ou torsional (oblique muscles). For each corresponding pair, the actions in diametrally opposite conditions of ocular fixation and gaze position are compared. For example, supradextroversion, with fixation of the right eye and infralevoversion with fixation of the left eye in order to compare the actions of the right superior rectus and of the left inferior rectus, respectively. The influence of the head tilt upon such actions is also analyzed. The paper also studies the synkinetic relationship between accommodation and convergence, proximal convergence, and the units of those functions.

Keywords: Strabismus; Eye movements; Optical rotation; Measures; Oculomotor muscles; Oculomotor nerve; Accommodation, ocular; Convergence, ocular; Eye diseases

\section{REFERÊNCIAS}

1. Pratt-Johnson JA, Tillson G. Management of strabismus and amblyopia. New York: Thieme; 1994
2. Bicas HEA. Oftalmologia: fundamentos. São Paulo: Contexto; 1991.

3. Prieto Diaz J, Souza-Dias C. Estrabismo. $3^{\text {a }}$ ed. La Plata: J. Poch; 1996.

4. Burde RM. The extraocular muscles. Part I: Anatomy, physiology, and pharmachology. In: Moses RA, editor. Adler's physiology of the eye: clinical application. Saint Louis: Mosby; 1975. p.86-122.

5. Alpern M. Movements of the eye. In: Davson H, editor. The eye- muscular mechanisms. $2^{\text {nd }}$ ed., New York \& London: Academic Press; 1969.v.3, p.1-214.

6. Burde RM. The extraocular muscles. Part II: Control of eye movements. In Moses RA, editor. Adler's physiology of the eye; clinical application. Saint Louis: Mosby; 1975. p.123-65.

7. Bicas HEA. Consideraciones sobre los factores mecánicos en la acción de los músculos oculares. Acta Estrabol 1996;25:161-78.

8. Bicas HEA. Estudos da mecânica ocular. II - Análise das rotações oculares Arq Bras Oftalmol 1981;44:26-36.

9. Bicas HEA. Estudos da mecânica ocular. I - Sistemas de definição das rotações oculares. Arq Bras Oftalmol 1981;44:18-25.

10. Bicas HEA. Estudos da mecânica ocular III - Componentes vetoriais da força de cada músculo nas rotações oculares. Arq Bras Oftalmol 1981;44:37-43.

11. Miller JM, Demer JL. Use of biomechanical modeling in strabismus. In: $12^{\circ}$ Congreso del Consejo Latinoamericano de Estrabismo. Buenos Aires; 1996 Anales; 1996. p.485-91.

12. Bicas HEA. Interpretação dos mecanismos de ação dos procedimentos cirúrgicos em estrabismo. In: $12^{\circ}$ Congreso del Consejo Latinoamericano de Estrabismo. Buenos Aires; 1996. Anales. Buenos Aires; 1996. p.297-306.

13. Parks MM. Isolated cyclovertical muscle palsy. Arch Ophthalmol 1958;60:1027-35

14. Bicas HEA. Diagnóstico do estrabismo vertical paralítico. Estudo comparativo da manobra de Parks e da manobra de Bicas. In: $19^{\circ}$ Congresso Brasileiro de Oftalmologia. Rio de Janeiro; 1977. Anais. São Paulo; 1977. p.359-76.

15. Bicas HEA. Discussion of some diagnostic tests for vertical deviations. Rev Latin Am Estrab 1979;3:67-76.

16. Kushner BJ. Errors in the three-step test in the diagnosis of vertical strabismus. Ophthalmology 1989;96:127-32.

17. Kushner BJ. Diagnosis of isolated cyclovertical muscle palsies according to the method of Bicas. Binocul Vis Strabismus Q 1994;9:255-60.

18. Bicas HEA. Estrabismos - Noções sobre tópicos relevantes. In: Rodrigues MLV, Dantas AM, editors. Oftalmologia clínica. 2a ed. Rio de Janeiro: Cultura Médica; 2001. p.215-29.

19. Schachar RA, Huang T, Huang X. Mathematic proof of Schachar's hypothesis of accommodation. Ann Ophthalmol 1993;25:5-9.

20. Schachar RA, Cudmore DP, Black TD. Experimental support for Schachar's hypothesis of accommodation. Ann Ophthalmol 1993;25:404-9.

21. Schachar RA, Cudmore DP, Torti R, Black TD, Huang T. A physical model demonstrating Schachar's hypothesis of accommodation. Ann Ophthalmol 1994;26:4-9.

22. Wilson RS. Does the lens diameter increase or decrease during accommodation? Human accommodation studies: a new technique using infrared retro-illumination video photography and pixel unit measurements. Trans Am Ophthalmol Soc 1997;95:261-7.

23. Burd HJ, Judge SJ, Flavell MJ. Mechanics of accommodation of the human eye. Vision Res 1999;39:1591-5.

24. Ludwig K, Wegscheider E, Hoops JP, Kampik A. In vivo imaging of the human zonular apparatus with high-resolution ultrasound biomicroscopy. Graefes Arch Clin Exp Ophthalmol 1999;237:361-71.

25. Mathews S. Scleral expansion surgery does not restore accommodation in human presbyopia. Ophthalmology 1999;106:873-7.

26. Bicas HEA, Nóbrega JFC. Resposta acomodativa à convergência induzida por prismas em pessoas normais. Bol Assoc Bras Ortopt 1973;5:46-51.

\section{ABO ELETRÔNICO}

Novo site

\section{Acesso: http://www.abonet.com.br}

